\title{
Hardtwig, Wolfgang, Macht, Emotion und Geselligkeit. Studien zur Soziabilität in Deutschland 1500-1900
}

\section{Guillaume Garner}

\section{OpenEdition}

\section{Journals}

Édition électronique

URL : http://journals.openedition.org/ifha/6498

DOl : 10.4000/ifha.6498

ISSN : 2198-8943

Éditeur

IFRA - Institut franco-allemand (sciences historiques et sociales)

Référence électronique

Guillaume Garner, «Hardtwig, Wolfgang, Macht, Emotion und Geselligkeit. Studien zur Soziabilität in Deutschland 1500-1900 », Revue de l'IFHA [En ligne], Date de recension, mis en ligne le 01 janvier 2012, consulté le 22 septembre 2020. URL : http://journals.openedition.org/ifha/6498 ; DOI : https://doi.org/ 10.4000/ifha.6498

Ce document a été généré automatiquement le 22 septembre 2020.

(C)IFHA 


\title{
Hardtwig, Wolfgang, Macht, Emotion und Geselligkeit. Studien zur Soziabilität in Deutschland 1500-1900
}

\author{
Guillaume Garner
}

1 Ce volume regroupe neuf articles et contributions, publiées par W.H. entre 1984 et 2008 sur l'histoire de la sociabilité en Allemagne. Même si le genre de l'« histoire des mentalités » est peu ou prou représenté par deux études portant sur les valeurs de la jeunesse estudiantine, ces études se rattachent aux recherches menées à partir des années 1980 (sous l'égide notamment de Rudolf Vierhaus) sur les formes de sociabilité et notamment sur le concept d'association qui devient pendant la période des années 1750-1850 l'un des supports par lequel la sphère publique émergente entend affirmer son autonomie et articuler son désir de participation politique. Un texte est particulièrement représentatif de la démarche de l'auteur : il s'agit de l'article consacré aux concepts d'association, de société, de société secrète et de coopérative (« Verein, Gesellschaft, Geheimgesellschaft, Assoziation, Genossenschaft ») publié en 1990 dans le volume 6 des Geschichtliche Grundbegriffe dirigés par Otto Brunner, Werner Conze et Reinhart Koselleck.

2 De manière plus générale, W.H. s'attache à la période de la Sattelzeit définie par R. Koselleck et il souligne les nuances qu'il convient d'apporter à une vision qui oppose les formes de sociabilité modernes et contemporaines en rappelant les éléments de continuité qui existent entre les corporations et les associations, ou syndicats qui se forment pendant la première moitié du XIXe siècle. Au-delà des dichotomies simplificatrices, c'est précisément l'évolution (non linéaire) de ces formes de sociabilité que ces études entendent retracer, et c'est cette démarche qui fait tout l'intérêt de ce recueil.

$3 \mathrm{Au}$ vu de l'érudition manifestée par l'auteur, reconnu comme l'un des éminents spécialistes allemands de ces thématiques, on peut finalement manifester un regret : que l'historiographie de la question ne soit pas davantage prise en compte. Exacte dans les années 1980, l'affirmation qui ouvre le volume (« les recherches sur la sociabilité ne 
sont en Allemagne pas très nombreuses »-p. 9) a entre-temps mérité d'être largement corrigée, et il eût sans nul doute été intéressant de savoir comment W.H. a situé ses propres recherches par rapport à ce champ historiographique.

4 Guillaume Garner (ENS Lyon) 